is then passed through the liver, and in this way the organ can be preserved for up to 6 or 7 hours before being transplanted. At St Mary's Hospital in London a liver-shaped plastic box has been designed to keep the organ cool between removal and transplantation, and it seems that this will play a useful part in prolonging the useful life of the liver.

The simultaneous transplantation of heart and lungs would have several advantages, not the least of which is the reduction in time required for this operation compared with transplantation of the heart alone. The heart surgery team at the National Heart Hospital says that the heart transplant operation is the first of a series of operations leading to a combined heartlung transplant before the end of the year. Whether the recent achievement-and the resultant publicitywill in any way affect the recommendation in the Royal Commission report for the combination of the hospital with the so-called "Chelsea" group remains to be seen.

Meanwhile, in the United States the hunt for another transplantable organ is on, and attention is being focused on the spleen. In the current issue of World Medicine, Dr J. Norman of Harvard University reports success in arresting canine haemophilia in three animals by transplanting healthy spleens from animals of the same species. His suggestion that it may be possible for a non-haemophilic mother to donate her spleen to her haemophiliac son should, however, be treated with reserve, according to Dr E. E. Peacock, professor of surgery at the University of North Carolina.

\section{Arrow on the Ground}

Now that the demise of ELDO seems to be in sight, probably marking the end of European co-operation on ambitious space projects for some time at least, it is worth asking what the prospects are for a purely national British space programme. This, of course, depends on the availability of a launching rocket, the linchpin of space activities. As a basis for any programme Britain may undertake in the future, three satellite launch vehicles are on order from the SaundersRoe division of Westland Aircraft. They are Black Arrow launchers, based on the Black Knight ballistic test rocket, and roughly equivalent in capability to the American Scout rocket which last year launched Ariel 3.

Briefly, Black Arrow is a three stage rocket designed to launch satellites of about $240 \mathrm{lb}$ into a 300 mile polar orbit. The first and second stage engines are similar to the Black Knight design and use hydrogen peroxide and kerosene propellants; the third stage has a solid fuel. The first firing is expected to take place from Woomera in March next year, and will be to test the first and second stages, and the separation of the third stage motor together with its payload. The second and third firings, in the autumn next year and early in 1970, will be attempts at satellite launches.

Because the firings are primarily to test the rocket itself, the main function of the satellites carried during the two orbital attempts is to monitor the performance of the third stage. Radio beacons will be carried so that the orbit achieved can be precisely determined. Once the performance of the rocket itself has been proved, the emphasis will be on testing various components of satellite design. A satellite is planned which will test in orbit new telemetry, power supplies and various surface materials to control the temperature of satellites. No Black Arrows have so far been ordered for this stage of the project.

One of the roles envisaged for ELDO rockets in the future was the launching of communication satellites into geo-stationary orbits. Conjecture about Back Arrow fulfilling this objective has been based on the notion that a satellite in a near-Earth orbit could be gradually propelled out to more distant orbits by a so far unproved electric propulsion system. This contrasts with the technique hitherto used to achieve geo-stationary orbits, which is to convert a near-Earth

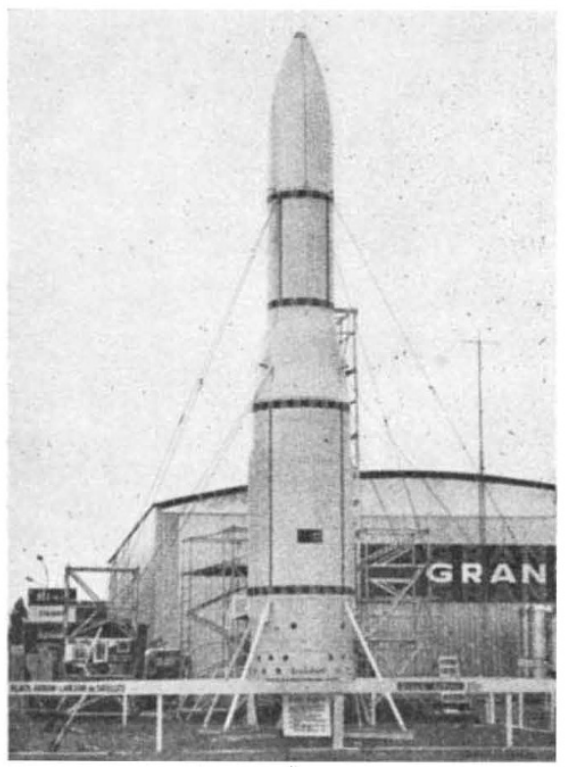

Black Arrow satellite launcher.

orbit into an elliptical orbit, with apogee at the 37,000 $\mathrm{km}$ altitude of geo-stationary orbits. The elliptical orbit is changed into a circular geo-stationary orbit by firing a motor at apogee.

An electric propulsion system involves the acceleration of ions by an electric field, using energy collected from solar radiation by arrays of solar cells. The advantage is that no fuel need be carried to change from a near-Earth orbit into a geo-stationary orbit; on the other hand, an array of solar cells large enough to gather sufficient energy from the Sun have to be incorporated into the satellite, although once a geostationary orbit has been achieved these are still available to power electronic systems on board the satellite. Bearing in mind the size of satellite which can be Jaunched into a near-Earth orbit, however, it seems that the launching of a geo-stationary communication satellite large enough to be practicable is beyond the capabilities of the Black Arrow project in its present form.

\section{ESRO-2 Launch}

A SECOND attempt to launch the satellite ESRO-2 is expected to be made on May 15 from the Western Test Range in California. The seven experiments on board the satellite are from universities and laboratories in Great Britain, France and the Netherlands, 
and are primarily concerned with solar astronomy and the study of cosmic rays. It is the first ESRO satellite to be launched; the launching of ESRO-1, which is devoted to an investigation of the polar ionosphere and aurorae, will probably be later this year. An earlier attempt at launching ESRO-2 took place almost a year ago-it was unsuccessful because exhaust gases burnt through the casing of the third stage engine of the Scout launcher. It must nevertheless be comforting to the designers of ESRO-2 that the satellite itself seemed to be working correctly during the abortive launch.

The orbit of ESRO-2, chosen to facilitate study of the Sun, will pass over the poles. The satellite will be launched into an orbital plane almost at right angles to the Earth-Sun line, and the plane of the orbit will rotate at the same rate as the apparent motion of the Sun around the Earth, so that the satellite will be in sunlight for most of the time. The perigee and apogee are $350 \mathrm{~km}$ and $1,100 \mathrm{~km}$, respectively, taking the satellite into the inner Van Allen belt.

\section{Testing, Testing}

For reasons of war and peace, the United States Atomic Energy Commission is stepping up the number of its tests of nuclear bombs. There will probably be twice as many tests in 1968 as there were last year, when 25 were announced and perhaps as many as 10 others took place. The one-megaton explosion that upset Mr Howard Hughes and Dr Barry Commoner among others last week is presumed to have been a step on the road to the thermonuclear warhead planned for the Sentinel anti-ballistic missile system.

The test, although it shook chandeliers in Las Vegas 100 miles away, did none of the dire things predicted; it did not start movement along the San Andreas fault in California, nor did it release radiation nor cause any serious damage to buildings. Nonetheless the explosion did seem in bad taste, coinciding with the opening of the General Assembly's debate on the non-proliferation treaty. But the AEC is making no bones about its plans to have more tests, and bigger ones. According to Dr Glen Seaborg, two new test sites are being developed, at a cost of about $\$ 40$ million. The intention clearly is to satisfy some of the AEC's crities who were more vociferous about the recent test than they have been for a long time. Yet the new sites-one at Hot Creek Valley in central Nevada, the other on Amchitka Island in the Aleutians-may not be beyond reproach. A calibration test conducted at Hot Springs broke some windows in northern California and Amchitka Island has been a government preserve for sea otters and seals.

Most of the new weapons tests are going to be in what the AEC describes coyly as "well above the intermediate range". Last month's explosion at the bottom of a 3,800 foot sealed shaft was the biggest ever held in the United States, above or below ground. Some of those who objected to it, in addition to Dr Commoner's Committee for Environmental Information in St Louis, were the Federation of American Scientists (with 2,200 members), the Women's Strike for Peace and a division of the United Auto and Aerospace Workers' Union.

But in the AEC's view the tests are safe. The geological structure of Nevada is such that most of the shock waves travel to the cast and the likelihood of radiation escaping is thought to be small. The AEC maintains that on the few occasions when there has been what it calls "venting", the radiation has not crossed the American frontiers. It has, on the other hand, inquired of the Soviet Union about three accidental discharges of radioactive debris which, after Russian tests, was carried beyond the borders of the Soviet Union. The Russians in turn have inquired about three of the Amcrican tests, but no formal protests have been mede on either side.

The AEC meanwhile is looking to its own future by practising techniques for mining metals and minerals by explosion; some day it might depend on commercial contracts for nuclear detonations to keep itself alive. The first such test to be done in partnership with private industry looks to have been a success. Project Gasbuggy, set off last December in the sandstone formations near Farmington, New Mexico, created an artificial chimney in the crushed rock. The hope of the El Paso Natural Gas Company, which shared the cost with the AEC, is that gas will have accumulated in the chimney to such an extent that its recovery will be relatively easy and cheap.

So far, samples of the gas which have been sent for analysis to the Lawrence Radiation Laboratory in Livermore, California, have shown little or no tritium or radioactive iodine. Any appreciable contamination of the gas could kill the outlook for its commercial production by such explosions. The final report on Gasbuggy will not be released for a year or more and actual measurements of the gas flow will not begin until the summer. But if things have gone as well as they seem to have done, Gasbuggy could be followed soon by five other commercial tests on the AEC's waiting list.

The culmination of the AEC's commercial ambitions would be the blasting of a new canal across the Isthmus of Panama. An Atlantic-Pacific Interoceanic Canal Study Commission is mulling over the diplomatic and technical obstacles to detonating thousands of nuclear explosions near a populated area. To provide some test information for this committee, an explosion confusingly labelled Project Buggy was performed in Nevada in January. Five nuclear explosives were buried in a row 135 feet deep and about 150 feet apart. The result was a trench 80 feet deep, 300 feet wide and 900 feet long - not quite enough for a new Panama Canal, but a beginning. About five per cent of the radioactiv. ity produced escaped from the crater; AEC officials found this acceptable. Whether Panamanians or the signatories to the test-ban treaty would agree is another matter, but it is not entirely out of the question that such a procedure would be agreed on.

\section{Ad Astra by Bus}

THe British aircraft industry is having its most cheerful year for a very long time. For once, it seems, there have been more orders than cancellations, and for the time being the merger (Government inspired) between Hawker-Siddeley and the British Aircraft Corporation is off. The two most important successes have been the selling of the Rolls-Royce RB 211 engine for the Lockheed airbus, and the order announced last week by BAC for guided missile systems for Libya. In the first two months of the year, the Society of British 